\title{
Foreword: Special Issue on Scholarly Teaching
}

\author{
Kazuko Hiramatsu \& Michal Temkin Martinez*
}

This special issue of Proceedings of the Linguistic Society of America (PLSA) contains peerreviewed papers presented during an organized session on scholarly teaching at the 2021 LSA Annual Meeting. The session was organized by an NSF-sponsored Faculty Learning Community that was formed in 2019 to build capacity among a cohort of linguists to advocate for scholarly teaching and the scholarship of teaching learning (SoTL). ${ }^{1}$

Over the past two decades, interest in pedagogy in our field has increased at the individual and disciplinary level. Members of the LSA have engaged in committee work and formed a Special Interest Group (SIG) to help the field advance its understanding of scholarly teaching: a continual reflection of our teaching practices with the goal of improving it and enhancing student learning. The shift from scholarly teaching to the scholarship of teaching and learning (SoTL; Felten 2013) - the dissemination of our work through publications and conference presentations - is still in its infancy in our field. Unlike many other science disciplines, SoTL is still an emerging research area, both in recognition and practice (Witman \& Richlin 2007).

The sudden shift to emergency remote teaching and learning during the COVID-19 pandemic highlighted significant gaps in our collective understanding of scholarly teaching, especially as linguistic pedagogy relates to issues of justice, equity, diversity, and inclusion (JEDI). This shift required flexibility and rapid adjustments in our classrooms, by both instructors and students, and heightened the importance and value of critical self-reflection of our teaching in support of our students. In the best cases, linguists rose to meet the challenge using holistic and traumainformed ways. In less ideal circumstances, linguists focused their energy on the use of new technology to deliver the same content, with little consideration for the larger context of collective trauma.

The range of teaching and learning adjustments during the pandemic emphasizes the lack of a shared understanding of equity- and evidence-based approaches to pedagogy in our field. Through public opportunities for conversation about scholarly teaching, we hope more instructors will rethink their approaches to teaching linguistics and what their students might need beyond an instructor's disciplinary expertise and content delivery. Through this process, we can also understand the importance of understanding and incorporating evidence-based approaches to pedagogy not just in our individual classrooms but more broadly across our field of linguistics.

One of the goals of our FLC is to increase the availability and quality of SoTL-related materials, and our organized session was an initial step towards this. The organized session provided a space for linguists to share and reflect on strategies used during the shift to remote teaching/learning, to discuss how these strategies are or could be informed by evidence-pedagogical practices, and to reflect on the effect of the shift on teaching and learning in the field of linguistics.

Presenters at the peer reviewed POSTER session were invited to submit their work for this special issue of the PLSA. We intentionally chose to include a second review process to build

\footnotetext{
*Authors: Kazuko Hiramatsu, University of Michigan-Flint (kazukoh@umich.edu) \& Michal Temkin Martinez, Boise State University (michaltmartinez@boisestate.edu).

${ }^{1}$ This material is based upon work supported by the National Science Foundation under Grant No. 1924593. Any opinions, findings, and conclusions or recommendations expressed in this material are those of the authors and do not necessarily reflect the views of the National Science Foundation.
} 
capacity in our community of scholarly teachers, with the hope of building towards SoTL in the future. We would like to thank the following FLC members who served as reviewers during this important process:

Christina Bjorndahl (Carnegie Mellon University)

Reed Blaylock (University of Southern California)

Kristin Denham (Western Washington University)

Jessi Grieser (University of Tennessee, Knoxville)

Wesley Leonard (University of California, Riverside)

Michael Rushforth (University of Texas, San Antonio)

Rosa Vallejos (University of New Mexico)

Lynsey Wolter (University of Wisconsin, Eau Claire)

The special issue begins with the findings of an LSA survey conducted by members of our FLC on teaching and learning during the spring 2020 shift to remote instruction. The rest of papers follow the same order as the POSTER panel, and are grouped by three main topics: course design, learning activities, and teaching topics.

We are proud of the work that is included in this special issue, and we hope that readers will find the short papers accessible and helpful in their reflections about teaching. We invite you to remain engaged in our conversations on scholarly teaching by joining the SIG (https://tinyurl.com/LINGscholarlyteachingSIG) and by attending and participating in pedagogyrelated events and sessions.

\section{References}

Felten, Peter. 2013. Principles of good practice in SoTL. Teaching \& Learning Inquiry: The ISSOTL Journal 1(1). 121-125. https://doi.org/10.20343/teachlearninqu.1.1.121.

Witman, Paul D. \& Laurie Richlin. 2007. The status of the scholarship of teaching and learning in the discipline. The International Journal for the Scholarship of Teaching and Learning 1(1).14. 1-19. https://doi.org/10.20429/ijsotl.2007.010114. 